\title{
RESGATE DA HISTÓRIA DO ALEITAMENTO MATERNO NA CIDADE DE FEIRA DE SANTANA
}

\author{
Branda Cavalcante Dourado $^{1}$; Heli Vieira Brandão ${ }^{2}$ \\ 1. Bolsista PROBIC/UEFS, Graduanda em Medicina, Universidade Estadual de Feira de Santana, e-mail: \\ brandamed@gmail.com \\ 2. Orientadora, Departamento de Saúde, Universidade Estadual de Feira de Santana, e-mail: \\ helivb.fsa@gmail.com
}

PALAVRAS-CHAVE: Aleitamento materno; Feira de Santana; Banco de Leite Humano.

\section{INTRODUÇÃOO}

A Organização Mundial da Saúde (OMS) e o Fundo das Nações Unidas para a Infância e Adolescência (UNICEF) recomendam o aleitamento materno exclusivo (AME) desde o nascimento até o sexto mês de vida, sendo o aleitamento materno (AM) complementado por outros alimentos até os dois anos ou mais. O leite humano protege contra doenças alérgicas, desnutrição, diabetes mellitus, doenças digestivas, obesidade, cáries, entre outras (RAMOS et al., 2010). O AM promove a saúde física, mental e psíquica da criança, repercutindo em toda a vida do indivíduo. Para a mãe, amamentar auxilia na diminuição do sangramento uterino no puerpério, previne o câncer de mama e de ovário, além de ser um método natural de planejamento familiar.

A OMS em 2001 reconheceu a Rede Global de Bancos de Leite Humano como uma das ações que mais contribuíram para redução da mortalidade infantil no mundo na década de 1990. De 1990 a 2012, a taxa de mortalidade infantil no Brasil caiu 70,5\%.(Portal Brasil, 2017). O Brasil se destaca internacionalmente em $\mathrm{AM}$ e isso se deve às suas políticas, regulações, estratégias e iniciativas de educação para toda a população sobre a importância do aleitamento. O incentivo ao AM ocorre desde 1981, quando foi instituído o Programa Nacional de Incentivo ao Aleitamento Materno (PNIAM).

O presente estudo objetiva analisar a trajetória do AM e os fatores que contribuíram para a sua evolução, na cidade de Feira de Santana. Para isto, é necessário: entender o processo de implantação, funcionamento e contribuições dos Bancos de Leite Humano para o apoio, incentivo e promoção do AM; conhecer as principais atividades científicas que têm ocorrido para a difusão do AM, realizadas por instituições públicas (universidades, Bancos de Leite Humano (BLH's)) e privadas; analisar os indicadores de AM da cidade de Feira de Santana ao longo do tempo, comparando com outras cidades e estados do Brasil.

\section{METODOLOGIA}

Trata-se de estudo documental de abordagem exploratória. mediante a investigação, registro e análise dos fatos ocorridos ao longo do tempo. Como fonte de dados foram utilizados registros e documentos: folders de eventos científicos, livros, jornais, revistas, tabelas estatísticas, relatórios, documentos oficiais de hospitais, cartas, fotografias. A coleta de dados baseou-se nos seguintes pilares: 1. Descrição dos indicadores de AM de Feira de Santana ao longo do tempo, registrados em documentos científicos; 2. Levantamento das ações desenvolvidas pelos BLH's, Hospitais Amigos da Criança, Universidades, bem como a participação dos pediatras, que contribuíram para a evolução do AM na cidade. Nesta etapa, foram realizadas entrevistas com alguns profissionais de referência, que militam na área de AM; 3. Levantamento das eventos promovidos em escolas públicas e particulares da cidade sobre AM. 


\section{RESULTADOS E DISCUSSÃO}

Em novembro de 1987 foi implantado no Hospital Geral Clériston Andrade (HGCA) o primeiro BLH do Estado da Bahia, o Centro de Incentivo em Aleitamento Materno (CIAMA/BLH). A criação deste serviço foi fruto de uma decisão política da $2^{\circ}$ Diretoria Regional de Saúde da SESAB, na época dirigida pelo Dr. Colbert Martins Filho, em parceria com a Legião Brasileira de Assistência (LBA). Dra. Graciete Oliveira Vieira e Enfa. Suelly Pinto T. de Morais coordenaram o projeto.

Este BLH tem como missão coletar, pasteurizar e distribuir leite humano ordenhado; além de incentivar e promover o AM. Em 1991, foi qualificado pelo Ministério da Saúde, através do Programa Nacional de Incentivo ao Aleitamento Materno/PNIAM e do Instituto Fernandes Figueiras (referência nacional em BLH), como Centro de Referência em Aleitamento Materno do Estado da Bahia. Primeiramente o incentivo ao aleitamento esteve restrito as mães que frequentavam o $\mathrm{BLH}$, e posteriormente atingiu diversos segmentos: pré-natal, sala de parto, alojamento conjunto, berçário de risco, serviço de puericultura e pediatria.

No intuito de atender a população em geral, o BLH do HGCA lançou campanhas educativas em televisão, rádios, jornais, outdoor, cartazes, adesivos para carro, ampliando o território de atuação. Foram realizados trabalhos de conscientização nas escolas, a fim de evitar o desmame precoce através da educação de alunos e professores. Em 1996, foi aprovado e sancionado pelo então prefeito José Raimundo de Azevedo o projeto de lei $\mathrm{n}^{\circ}$ 60/96, que dispõe sobre a introdução do tema aleitamento nos currículos escolares no município de Feira de Santana. Em março de 1997, a então deputada estadual Eliana Boaventura deu entrada no projeto de lei $\mathrm{n}^{\circ} 11.056 / 97$, que dispõe sobre a introdução de noções sobre AM na rede estadual de ensino.

Para sensibilizar profissionais de saúde foram realizados vários eventos, como jornadas, encontros e cursos, de acordo com a necessidade de capacitação permanente para manejo da lactação e amamentação, principalmente para técnicos em Banco de Leite Humano.

Em agosto de 1997 foi lançado o Projeto Carteiro Amigo pelo CIAMA/BLH do HGCA, que teve como objetivos: reduzir a morbimortalidade infantil na cidade de Feira de Santana e regiões vizinhas, aumentar a prevalência do AME até o $6^{\circ}$ mês de vida e divulgar a prática do $\mathrm{AM}$ na comunidade. Sua estratégia de ação foi: distribuição de folders pelos carteiros, durante a Semana Mundial de Aleitamento Materno (1 a 7 de agosto), com informações básicas sobre AM. Para cumprir essa estratégia, seria preciso: capacitar todos os carteiros, com cursos de no mínimo 2 horas, ministrados pela equipe do CIAMA/BLH; utilização de bonés e camisas pelos carteiros com o tema da campanha: "Amamentação - Sele esta ideia"; formatar os folders na forma de cartão postal. Durante a Semana Mundial de Aleitamento Materno de 1997, foram distribuídos 50.000 cartões postais, divulgando o AM.

Em setembro de 1998 foi lançado o Projeto Bombeiro Amigo pelo CIAMA/BLH do HGCA, contando com parceria do Corpo de Bombeiros de Feira de Santana. Seus objetivos foram: contribuir com a coleta do leite humano; atender as mães com dificuldades na amamentação, em seu domicílio; aumentar a prevalência do AME até o $6^{\circ}$ mês de vida, e estendê-lo até os 2 anos de idade; e conscientizar as gestantes e nutrizes sobre a importância do AM para o crescimento e desenvolvimento do lactente. As bombeiras foram treinadas com curso de manejo da lactação e amamentação com aulas teóricas e práticas, para posteriormente realizarem coleta domiciliar de leite humano, utilizando veículo do BLH e atenderem mães com dificuldades no processo da amamentação. 
O CIAMA/BLH desenvolveu atividades de extensão propostas no Projeto de Incentivo ao Aleitamento envolvendo:profissionais e estudantes universitários da área de saúde; professores e estudantes de escolas públicas; mães, comunidade e gestores.

Em ação comemorativa à Semana Mundial da Amamentação, iniciativa da Aliança Mundial para Ação em Aleitamento Materno (WABA) o CIAMA/BLH do HGCA em ação conjunta com o Programa de Pós-Graduação em Saúde Coletiva da Universidade Estadual de Feira de Santana e Secretaria de Educação do município, desenvolvem anualmente o Encontrinho de Aleitamento Materno em escolas públicas, desde 2008. Os Encontrinhos de Aleitamento Materno de Feira de Santana têm o propósito de contribuir, a longo prazo, com a promoção da amamentação, importante fator redutor da morbimortalidade infantil por favorecer práticas alimentares saudáveis e assegurar $\mathrm{o}$ bom crescimento e desenvolvimento da criança. A população-alvo dos Encontrinhos são crianças, adolescentes, educadores e pais ou responsáveis. Podem ser realizados no Auditório Central da UEFS e/ou nas escolas públicas ou particulares. O evento caracteriza-se pela distribuição de material didático e lúdico sobre o tema, proporcionando concursos e disputas que auxiliam na apreensão do conhecimento.

No balanço das atividades do CIAMA/BLH entre 1987-2015, tem-se como indicadores de excelência, a coleta de 13.339 litros de leite humano, a distribuição de 12.283 litros de leite para 9.209 crianças, 16.102 mães doadoras matriculadas neste período, 137.338 mulheres atendidas com relação às dificuldades com o manejo da lactação e amamentação, e 56.539 exames bacteriológicos realizados no leite humano coletado. No mesmo período foram treinados 667 profissionais de nível superior, entre médicos, enfermeiros, nutricionistas, assistentes sociais, fisioterapeutas, farmacêuticos, bioquímicos e dentistas, como também 1.480 profissionais da área de saúde de nível médio, totalizando 2.147 profissionais capacitados.

O BLH do Hospital Geral Clériston Andrade em Feira de Santana foi reconhecido em dezembro de 1993 pelo INAN/MS como Centro de Referência em Aleitamento Materno e Em março de 1994, houve o credenciamento pela UNICEF/MS como o $1^{\circ}$ Hospital Amigo da Criança do Estado da Bahia, $3^{\circ}$ do Nordeste e $4^{\circ}$ do Brasil.

De igual importância foi a criação do BLH do Hospital Inácia Pinto dos Santos, denominado como Hospital da Mulher. No ano de 1990, o Dr. Carlos Andrade Sampaio, Secretário de Saúde do município de Feira de Santana (1989-1990) procurou Dra. Graciete Vieira e Dra. Iracema Brandão para coordenar a implantação do Hospital da Mulher, que foi inaugurado no mês de janeiro de 1992. Elas aceitaram o convite mediante a contrapartida de criação de um BLH nesta unidade. Em março de 1992, o BLH recebeu a visita técnica do Dr. João Aprígio Guerra de Almeida (engenheiro de alimentos e mestre em microbiologia), tempo em que ele participava da programação científica do $1^{\circ}$ Simpósio de Gastrenterologia Pediátrica e Nutrição e $1^{\circ}$ Jornada de Aleitamento Materno de Feira de Santana.

A duração média da amamentação em Feira de Santana em 1996 foi de 9 meses (GRACIETE et. al., 1998). Comparando alguns desses dados com os disponíveis para o país, a região ou o estado, os resultados desta pesquisa demonstraram uma grande adesão das mães de Feira de Santana à utilização do AM. No interior da Bahia, em 1992, a duração média da amamentação foi de 5 meses; em Sergipe, em 1994, 4 meses (SILVEIRA, J.A.C.; GUIMARÃES, A.M.A., 1994); em áreas urbanas de Sergipe, em 1996, 6 meses (UNICEF, 1995); em Salvador, em 1996, 6 meses (SISVAN-BA, 1996); em Itabuna, em 1996, 9 meses.

O AM na primeira hora de vida está associado a uma redução de $44 \%$ a $45 \%$ das mortes neonatais de todas as causas e de infecção (DEBES et al., 2013). O aumento desse indicador em Feira de Santana pode ter contribuído para que este município tenha demonstrado a maior diminuição da taxa de mortalidade neonatal no estado da Bahia, 
passando de 27,8 / 1.000 nascidos vivos em 2006 para 11,3 / 1.000 em 2012 (Secretaria de Saúde da Bahia, 2017).

\section{CONCLUSÃO}

Feira de Santana apresenta alta prevalência de AM, resultado do contínuo incentivo ao AM desenvolvido pelos BLH's do HGCA e HIPS, ambos os hospitais públicos credenciados como "Amigos da Criança". Ademais, há relevância social nos eventos científicos e projetos apoiados por diversos segmentos da sociedade (Corpo de Bombeiros, Correios, escolas, universidade, serviços de saúde, imprensa) para fortalecer e proteger a prática do AM.

Foram analisadas intervenções exitosas que fizeram progredir os índices de AM em Feira de Santana, servindo como instrumento de disseminação desta prática e modelo para outros estados brasileiros e outros países.

\section{REFERÊNCIAS}

RAMOS, C.V., ALMEIDA, J.A.G., SALDIVA, R.D.M., PEREIRA, L.M.R., ALBERTO, N.S.M.C. Prevalência do Aleitamento Materno Exclusivo e os fatores a ele associados em crianças nascidas nos Hospitais Amigos da Criança de Teresina - Piauí. Rev Epidemiol Serv Saúde 2010; 19(2): 115-124.

Portal Brasil, 2017. Brasil é referência mundial em aleitamento materno. Disponível em: <http://www.brasil.gov.br/saude/2017/08/brasil-e-referencia-mundial-emaleitamento-materno>. Acesso em: 28 de novembro de 2017.

VIEIRA, G.O., GLISSER, M., ARAÚJO, S.P.T., SALES, A.N. Indicadores do aleitamento materno na cidade de Feira de Santana, Bahia. Breastfeeding indicators in the city of Feira de Santana, Bahia, Brazil. Jornal de Pediatria, Rio de Janeiro, Vol. 74, $\mathrm{N}^{\circ} 1.0021-7557 / 11.1998$.

SILVEIRA, J.A.C., GUIMARÃES, A.M.A. Diagnóstico de saúde materno-infantil no estado de Sergipe. Aracaju: Secretaria do Estado de Saúde de Sergipe,1994.

UNICEF- Fundo das Nações Unidas para a Infância. Pesquisa de saúde infantil nos bairros São Carlos e Jardim Centenário - Aracaju: UNICEF,1995.

SISVAN-Ba. Relatórios de pesquisas sobre indicadores do aleitamento materno.

Salvador: Secretaria de Saúde do estado da Bahia, 1996.

DEBES, A.K., KOHLI, A., WALKER, N., EDMOND, K., MULLANY, L.C. Tempo para iniciar a amamentação e mortalidade e morbidade neonatal: uma revisão sistemática. BMC Public Health. 2013; 13: S3-19.

Secretaria de Saúde da Bahia. Disponível em:

<http://webcache.googleusercontent.com/search?q=cache:InKv9yL3FuEJ:www.saude.b a.gov.br/dab/BAMonitoramentoTx\%2520MortalidadeNeonatal.xls+\&cd=4\&hl=pt$\underline{B R \& c t=c \operatorname{lnk} \& g l=b r \& c l i e n t ~}=$ firefox-a $>$ Acesso em: 08 de dezembro de 2017. 